\title{
Microstructural evolution in Mg-3Gd during accumulative roll-bonding
}

Luo, Xuan; Feng, Zongqiang; Yu, Tianbo; Huang, Tianlin; Li, Rongguang; Wu, Guilin; Hansen, Niels; Huang, Xiaoxu

Published in:

Materials Science and Engineering A

Link to article, DOI:

10.1016/j.msea.2019.138763

Publication date:

2020

Document Version

Peer reviewed version

Link back to DTU Orbit

Citation (APA):

Luo, X., Feng, Z., Yu, T., Huang, T., Li, R., Wu, G., Hansen, N., \& Huang, X. (2020). Microstructural evolution in Mg-3Gd during accumulative roll-bonding. Materials Science and Engineering A, 772, [138763].

https://doi.org/10.1016/j.msea.2019.138763

\section{General rights}

Copyright and moral rights for the publications made accessible in the public portal are retained by the authors and/or other copyright owners and it is a condition of accessing publications that users recognise and abide by the legal requirements associated with these rights.

- Users may download and print one copy of any publication from the public portal for the purpose of private study or research.

- You may not further distribute the material or use it for any profit-making activity or commercial gain

- You may freely distribute the URL identifying the publication in the public portal 


\section{Microstructural evolution in Mg-3Gd during accumulative roll-}

\section{bonding}

Xuan Luo ${ }^{\mathrm{a}}$, Zongqiang Feng ${ }^{\mathrm{a}, \mathrm{b} *}$, Tianbo $\mathrm{Yu}^{\mathrm{c}}$, Tianlin Huang ${ }^{\mathrm{a}, \mathrm{b}}$, Rongguang $\mathrm{Li}^{\mathrm{d}}$, Guilin $\mathrm{Wu}^{\mathrm{a}, \mathrm{b}, * *}$, Niels Hansen ${ }^{\mathrm{a}, \mathrm{e}}$ and Xiaoxu Huang ${ }^{\mathrm{a}, \mathrm{b}, \mathrm{c}}$

${ }^{a}$ International Joint Laboratory for Light Alloys (MOE), College of Materials Science and Engineering, Chongqing University, Chongqing 400044, China;

b Shenyang National Laboratory for Materials Science, Chongqing University, Chongqing 400044, China;

${ }^{c}$ Department of Mechanical Engineering, Technical University of Denmark, DK-2800 Kgs. Lyngby, Denmark;

d School of Materials Science and Engineering, Shenyang University of Technology, Shenyang 110870, China;

e Technical University of Denmark, Risø Campus, DK-4000 Roskilde, Denmark

* Corresponding author, Email: zqfeng@cqu.edu.cn

** Corresponding author, Email: wug1@cqu.edu.cn

Abstract: An Mg-3Gd (wt. \%) alloy has been deformed by accumulative roll bonding through four cycles to an equivalent strain of 3.2. The deformed microstructure has been fully characterized by advanced electron microscopy techniques and the mechanical properties are determined by tensile testing. Three characteristic microstructures have been identified and characterized as: cell blocks, twin blocks and nanograins, all with boundary spacings of 100-200 $\mathrm{nm}$. These structures illustrate a structural subdivision by low angle dislocation boundaries and high angle boundaries, which shows a clear resemblance with deformation microstructures in fcc and bcc metals deformed to high 
strain. The structural evolution has its origin in dislocation and twinning based plasticity which is quantified. The structure-strength relationship of this low-alloyed $\mathrm{Mg}-3 \mathrm{Gd}$ is analysed.

Keywords: Mg alloy, Accumulative roll bonding; Grain subdivision; Microstructure; Mechanical properties.

\section{Introduction}

Magnesium and its alloys are superior materials for lightweight automotive applications due to their high strength-density ratio [1,2]. However, a low strength and formability at ambient temperature limits their application. A characteristic of $\mathrm{Mg}$ alloys is their weaker response to precipitation and solid solution strengthening compared to fcc and bec metals $[3,4]$, but a large grain boundary strengthening points to grain size as an important strengthening parameter [5-7]. It follows that microstructural refinement by severe plastic deformation (SPD) [8,9], such as accumulative roll-bonding (ARB) [10,11], equal channel angular extrusion [12], high-pressure torsion [13], cyclic extrusion and compression [14], and repetitive extrusion-upsetting [15], may be an effective way to strengthen magnesium alloys.

In plastic deformation, dislocation glide is the dominant deformation mechanism supplemented by a limited amount of twinning in medium to high stacking fault energy fcc and bec metals, such as $\mathrm{Al}[16], \mathrm{Ni}[17]$ and $\mathrm{Fe}$ [18]. For magnesium, due to the low crystal symmetry and high mechanical anisotropy, both basal slip and twinning are important deformation modes at room temperature $[19,20]$. However, in Mg-RE (rare earth) alloys, many slip systems can be activated during plastic deformation [21-24], 
which may be affected by both processing and materials parameters [25], are expected to influence the microstructural refinement and mechanical properties.

Although SPD processed Mg alloys were extensively reported in the literature [11-13], limited transmission electron microscopy (TEM) studies have been done to quantify their microstructural evolution during SPD. It is therefore the objective of the present study to understand the microstructural refinement during SPD for a selected $\mathrm{Mg}$ alloy based on morphological observations and quantification of structural parameters by means of TEM. The analysis and the discussion of the experimental observations are guided by the hypothesis that the many slip systems activated in an Mg-RE alloy may produce deformation microstructures which have comparable features to those formed by plastic deformation of fcc and bcc metals [26-28], where multiple glide systems are activated during loading. Tensile testing is also conducted to investigate the effect of structural refinement on the mechanical properties.

\section{Experimental procedure}

An Mg-3Gd (wt. \%) was selected for the present study. The addition of 3 wt.\% Gd is mainly based on a previous study [29] which showed that Mg-Gd alloys with Gd concentrations in the range of $2.75 \%-4.65 \%$ exhibit good combinations of strength and tensile ductility, and similar and weak textures. An Mg-3Gd (wt. \%) rod ingot was produced with a diameter of $100 \mathrm{~mm}$ by casting pure $\mathrm{Mg}$ and $\mathrm{Mg}$-Gd master alloy in a columnar steel mould cavity using an electrical resistance furnace under Ar atmosphere. The cast ingot was homogenized at $450^{\circ} \mathrm{C}$ for $24 \mathrm{~h}$, followed by preheating at $450{ }^{\circ} \mathrm{C}$ for $30 \mathrm{~min}$ and extrusion to a plate with a thickness of $3 \mathrm{~mm}$. Following steps were hot rolling to $1 \mathrm{~mm}$ and annealing at $500{ }^{\circ} \mathrm{C}$ for $3 \mathrm{~h}$, producing initial sheet samples with an equiaxed recrystallized structure. The microstructure of the initial sheet sample with an average 
grain size of $45 \mu \mathrm{m}$ is shown in Fig. 1(a). A pole figure shows a weak $\{0002\}$ basal texture, see Fig. 1(b).

The $1 \mathrm{~mm}$ thick recrystallized sheet samples were used for ARB processing to apply high strains. Specimens with a length of $70 \mathrm{~mm}$, a width of $25 \mathrm{~mm}$ and a thickness of $1 \mathrm{~mm}$ were prepared from the sheet. Two such specimens were stacked and roll-bonded without lubrication. The sheet samples produced from the first ARB cycle were preheated at $400{ }^{\circ} \mathrm{C}$ for $8 \mathrm{~min}$ and roll-bonded again, keeping the rolling direction (RD) the same as the previous cycle. During preheating, the specimens were recrystallized to a grain size of about $10 \mu \mathrm{m}$. This procedure was repeated up to four ARB cycles and the samples produced were dubbed after the number of cycles $1 \mathrm{c}, 2 \mathrm{c}, 3 \mathrm{c}$ and $4 \mathrm{c}$.

Uniaxial tensile tests were performed in an AGX-50 tester system with a strain rate of $10^{-4} \mathrm{~s}^{-1}$ at room temperature. A laser extensometer was used to measure the sample strain during loading. Dog-bone shaped tensile specimens with a gauge length of $13 \mathrm{~mm}$ and cross-section of $5 \times 1 \mathrm{~mm}^{2}$ were cut with the tensile direction parallel to the RD. For each sample condition, three tensile specimens were tested.

Microstructures of ARB processed samples were characterized by scanning electron microscopy (SEM) and transmission electron microscopy (JEM-2100, FEI Tecnai F20). Both the SEM and TEM samples were cut from the longitudinal section containing the normal direction (ND) and RD. The SEM samples were prepared by mechanical polishing followed by electrochemical polishing in the AC2 solution. Thin foils for TEM were grinded and then ion-milled using Gatan PIPS 691. 

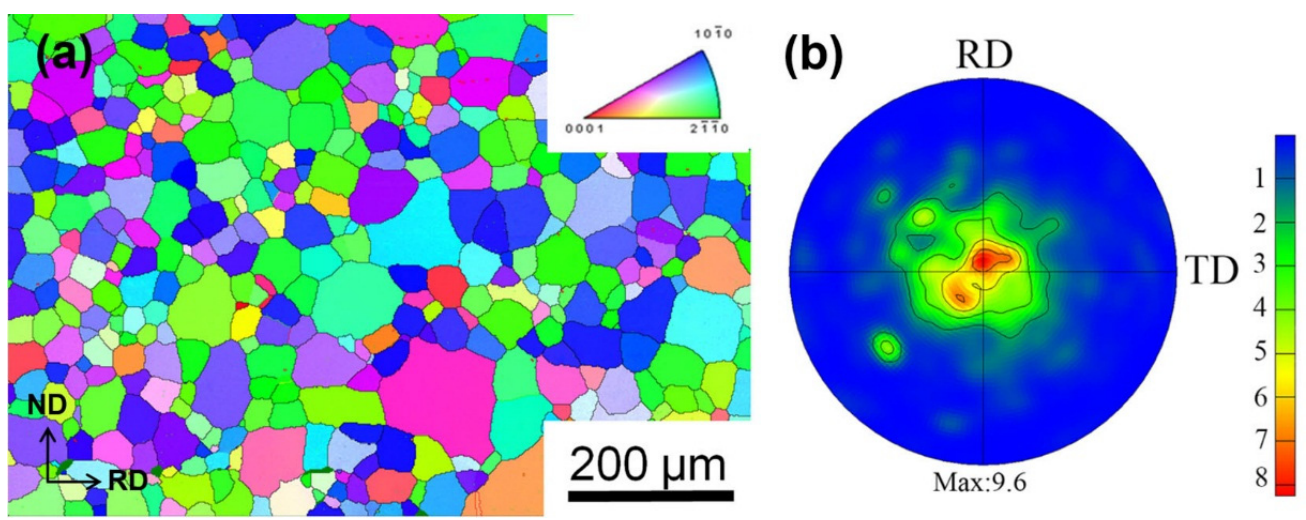

Fig. 1 (a) EBSD inverse pole figure showing the microstructure in the RD-ND section of the initial sheet sample $\left(500{ }^{\circ} \mathrm{C}, 3 \mathrm{~h}\right)$. The colours represent the crystallographic direction of the RD. (b) $\{0002\}$ pole figure showing the initial texture.

\section{Results}

\subsection{Microstructure}

Typical TEM images of the Mg-3Gd samples processed from $1 \mathrm{c}$ to $4 \mathrm{c}$ are shown in Fig. 2. As seen in Fig. 2(a), the microstructure of the 1c sample has been refined to the sub-micrometer scale. The microstructure is inhomogeneous with a relatively high concentration of deformation twins. However, the microstructures after 2c to 4c (Fig. 2(bd)) all show typical lamellar structures with lamellar boundaries (LBs) aligned along the RD. The $3 \mathrm{c}$ and $4 \mathrm{c}$ samples are therefore not further investigated leaving deformed $1 \mathrm{c}$ and 2c samples, respectively, where the latter shows a homogeneous microstructure subdivided by dislocation boundaries and twin boundaries. Therefore the $2 \mathrm{c}$ sample is chosen for a full characterization. 


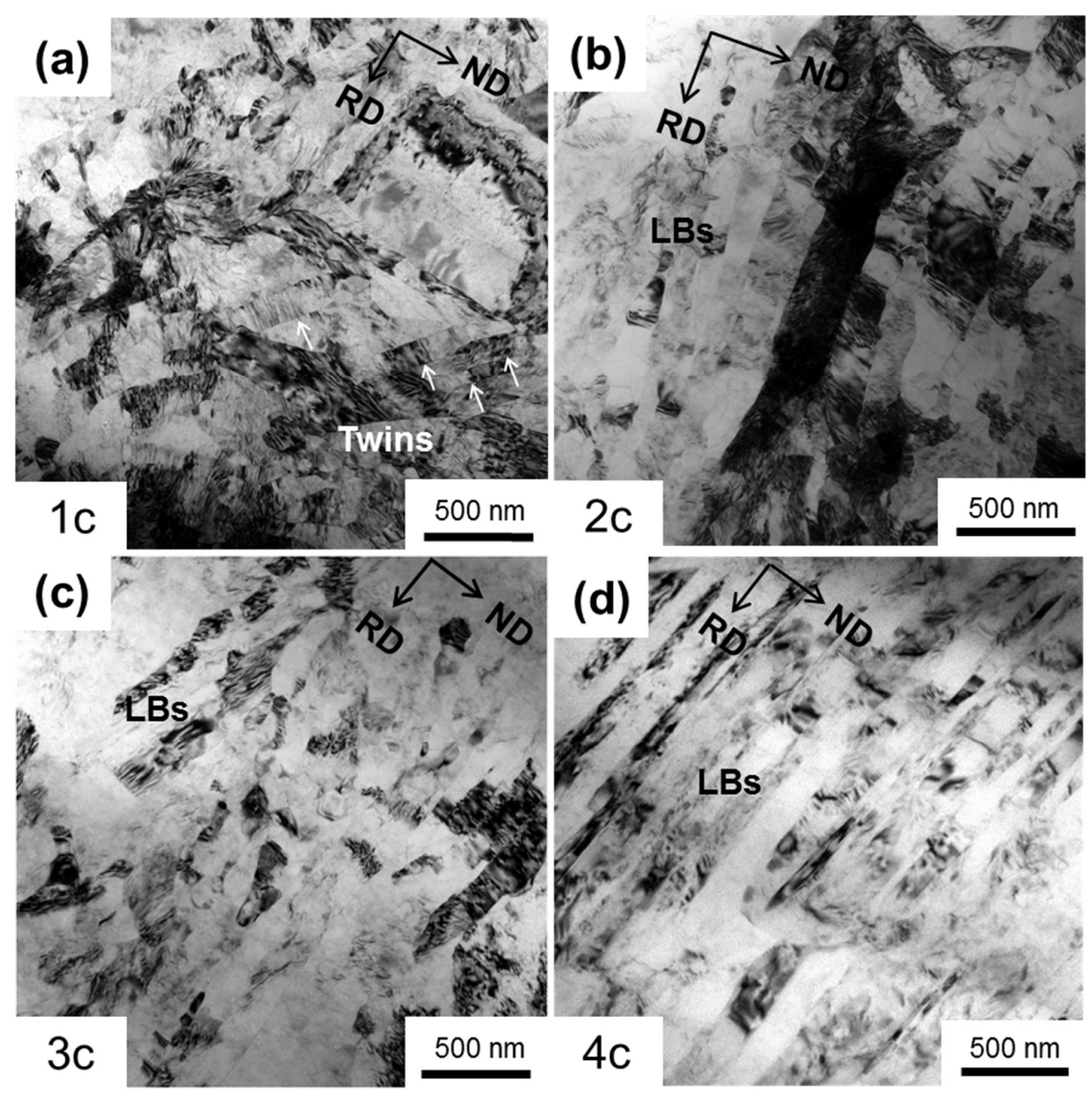

Fig. 2 TEM images of ARB samples, (a) 1c, (b) 2c, (c) 3c and (d) 4c. The RD and ND are marked on the images.

Fig. 3(a) shows an ECC image of the 2c sample. The structure is fully refined and the majority of the dislocation boundaries are aligned along the RD. Fig. 3(b, c) show TEM images of the lamellar structure and equiaxied grains in the $2 \mathrm{c}$ sample. Regular lamellar boundaries parallel to the RD are seen in Fig. 3(b). Fig. 3(c) shows a complex contrast including lamellae and equiaxied grains. More precise TEM characterization along $\langle 20\rangle$ in Fig. 3(d) shows that the matrix contains a small amount of deformation twins (marked by white lines), stacking faults (SFs) (marked by red arrows) and low angle 
boundaries (LABs, marked by yellow arrows). Inset in Fig. 3(d) shows the selected area electron diffraction (SAED) pattern of the circled area including the matrix and T1, and a LAB segment in the matrix is seen to approximately parallel to the basal plane (marked in blue).
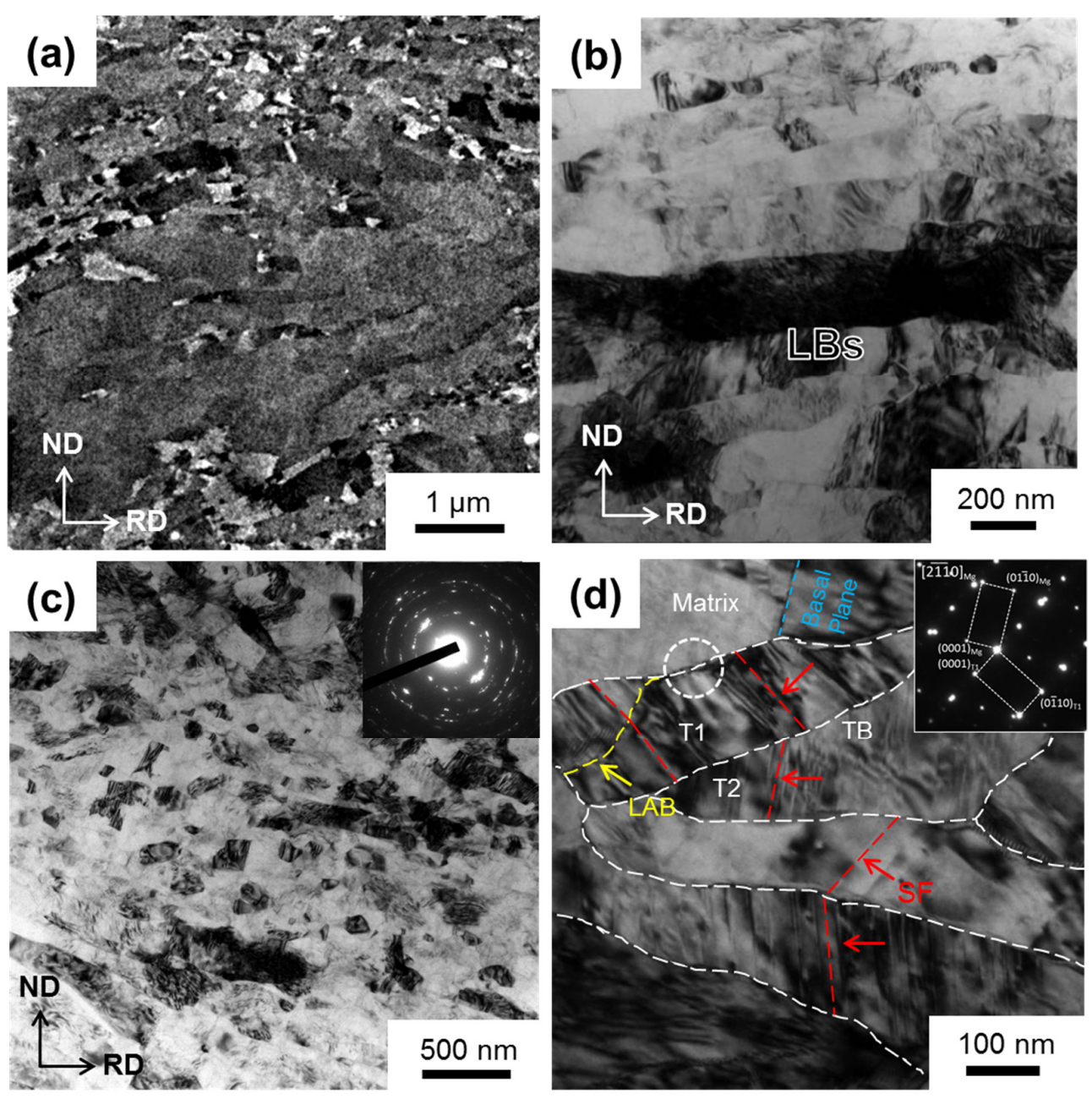

Fig. 3 (a) SEM ECC image showing the microstructure of the 2c sample, (b, c and d) TEM images of the $2 \mathrm{c}$ sample with characteristic dislocation structures ( $b$ and $c$ ) and twin structure (d). Note the different magnifications in the figures.

The deformation microstructure of the 2c sample as analyzed by TEM shows three characteristic features classified as: cell blocks, twin blocks and nanograins. The 
structural subdivision to the $100-200 \mathrm{~nm}$ scale is characterized by the boundary spacing distribution shown in Fig. 4. The three average spacings are comparable 190, 138 and 93 nm.
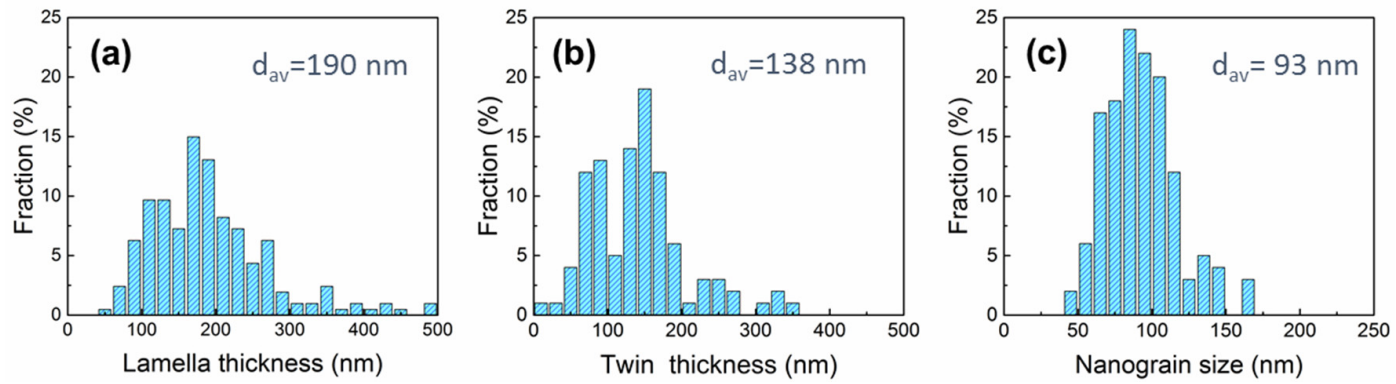

Fig. 4 The lamella (a) and twin (b) thicknesses measured perpendicular to boundaries. For equiaxed nanograins (c), the grain size is the equivalent circle diameter.

\subsubsection{Cell blocks}

A typical feature in fcc and bcc metals deforming by multiple glide is the cell block structure defined as a group of dislocation cells which is enclosed by extended boundaries. It follows that the lamellar structures shown in Fig. 2(b-d) can be classified as a cell block structures. An inspection of the volume between the lamellar boundaries shows a high density of low angle boundaries present in imperfect cell blocks [27]. Fig. 5 shows two examples of the lamellar structure. Dislocation boundaries (LABs and LBs) are found in deformed samples in a high area fraction. In Fig. 5, the structure is subdivided by parallel LABs on a very fine scale $(\sim 200 \mathrm{~nm})$. The basal plane is marked by white lines, and the insets show SAED patterns. Due to the activation of more slip systems in Mg-3Gd than in magnesium, non-basal slip is activated at room temperature, and two sets of slip-plane-aligned cell block structures (CB1 and CB2) were found in the deformed sample in Fig. 5(b). The finding that cell blocks form on different slip planes is in accord with previously characterized fcc and bcc metals [28]. 

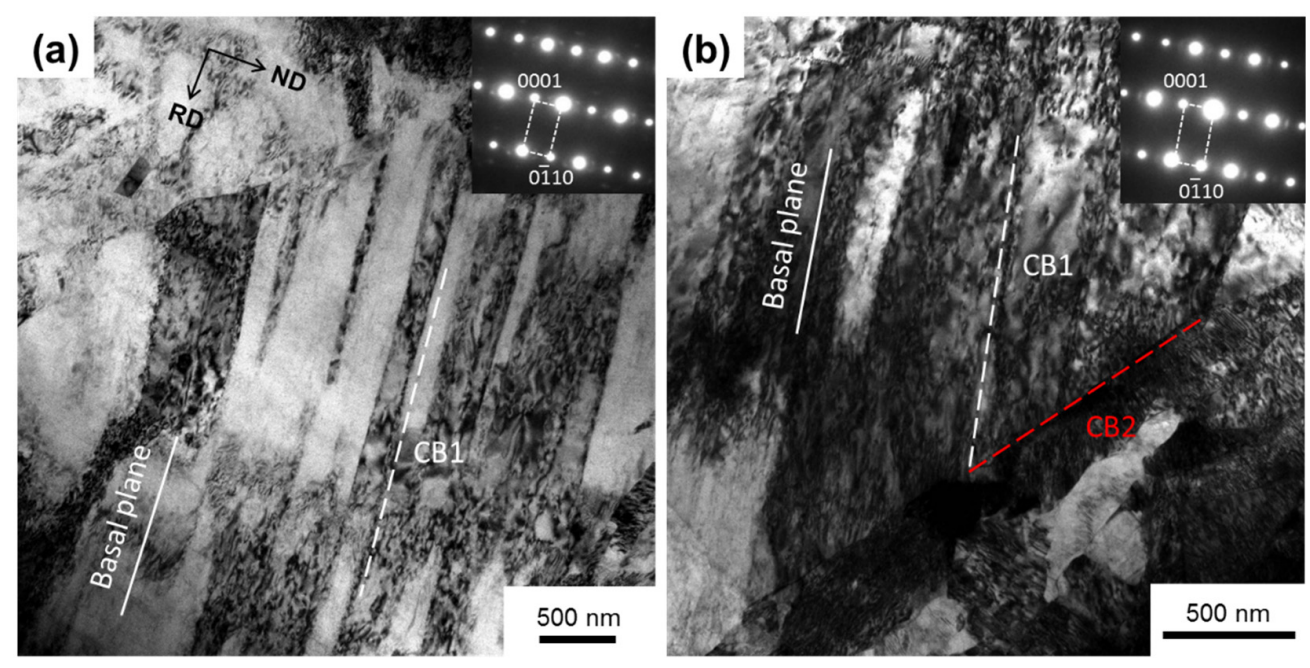

Fig. 5 TEM micrographs showing cell block structures including (a) basal-plane-aligned CB1 indicated by white dashed line, (b) two sets of dislocation structures (basal CB1 and non-basal CB2 indicated by white and red dashed lines, respectively).

\subsubsection{Twin blocks}

In magnesium alloys, twinning is typically observed together with dislocation structures after plastic deformation at room temperature [19,20]. Fig. 6 shows TEM images of twin structures in the $2 \mathrm{c}$ sample. Abundant twins and also twin-twin interactions can be seen. Such interactions are on a fine structural scale and may be part of the structural subdivision by twinning. The TEM structure in Fig. 6(c) is sketched in Fig. 6(d), which illustrates a structure of similar appearance as a cell block structure. A typical feature of a twin block is a volume enclosed by twin boundaries. An inspection of the volume between the twin boundaries shows a high density of low angle boundaries supplemental by twin boundaries and stacking faults (see Fig. 6(d)). 

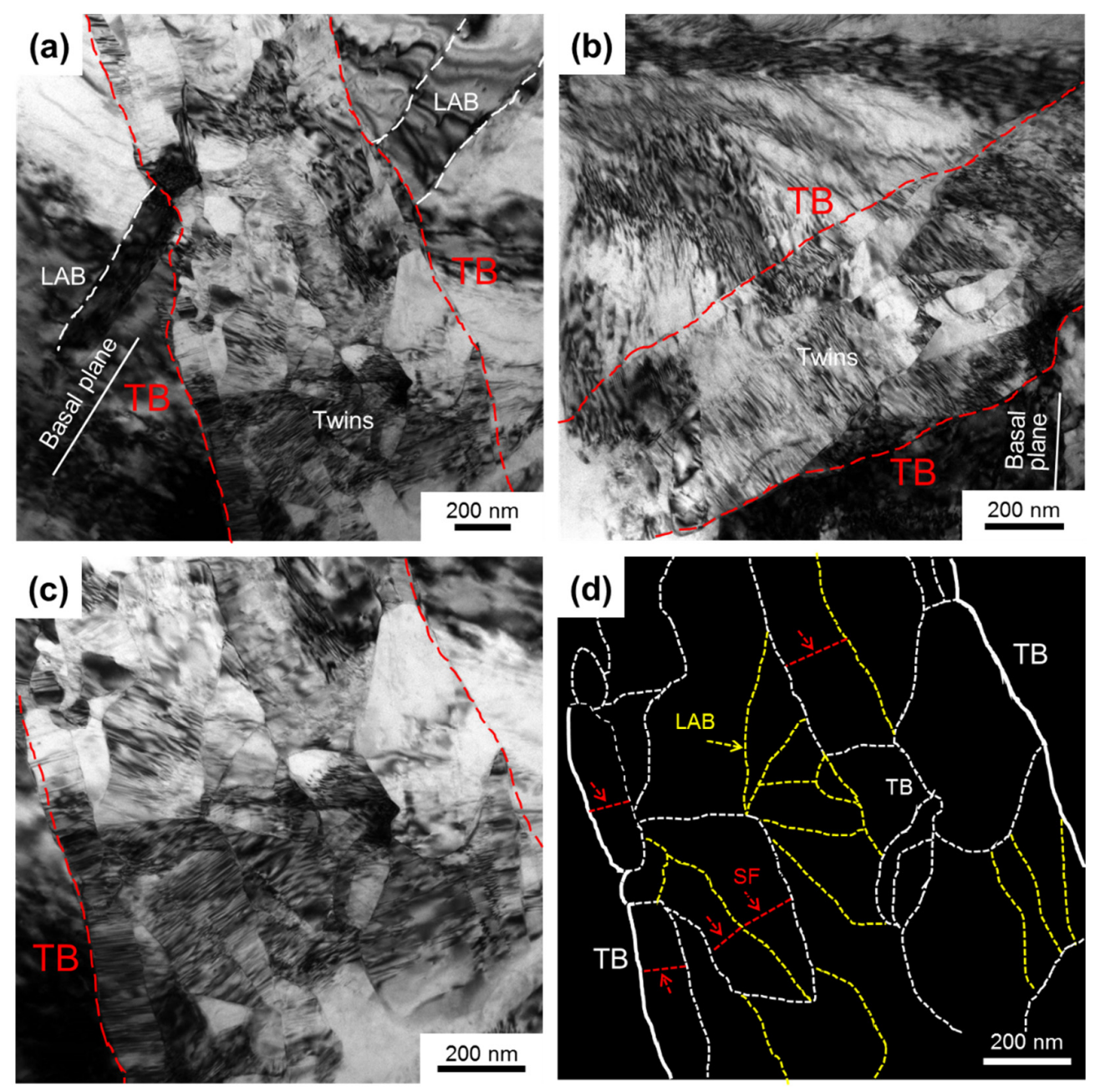

Fig. 6 TEM micrographs showing twin blocks ( $a, b$ and $c$ ) in the 2c sample. (d) A sketch showing adjacent twins (marked with white lines), SFs (red lines) and LABs (yellow lines) in a twin-block corresponding to Fig. 6c.

To further investigate the twin structure, high resolution TEM (HRTEM) has been applied. Within the twin blocks, nanograins can be identified, as shown in Fig. 7. Pronounced twin-twin interactions apparently take place during grain subdivision and may be origin of the nanograins. However, such a structural transition is for future research. 

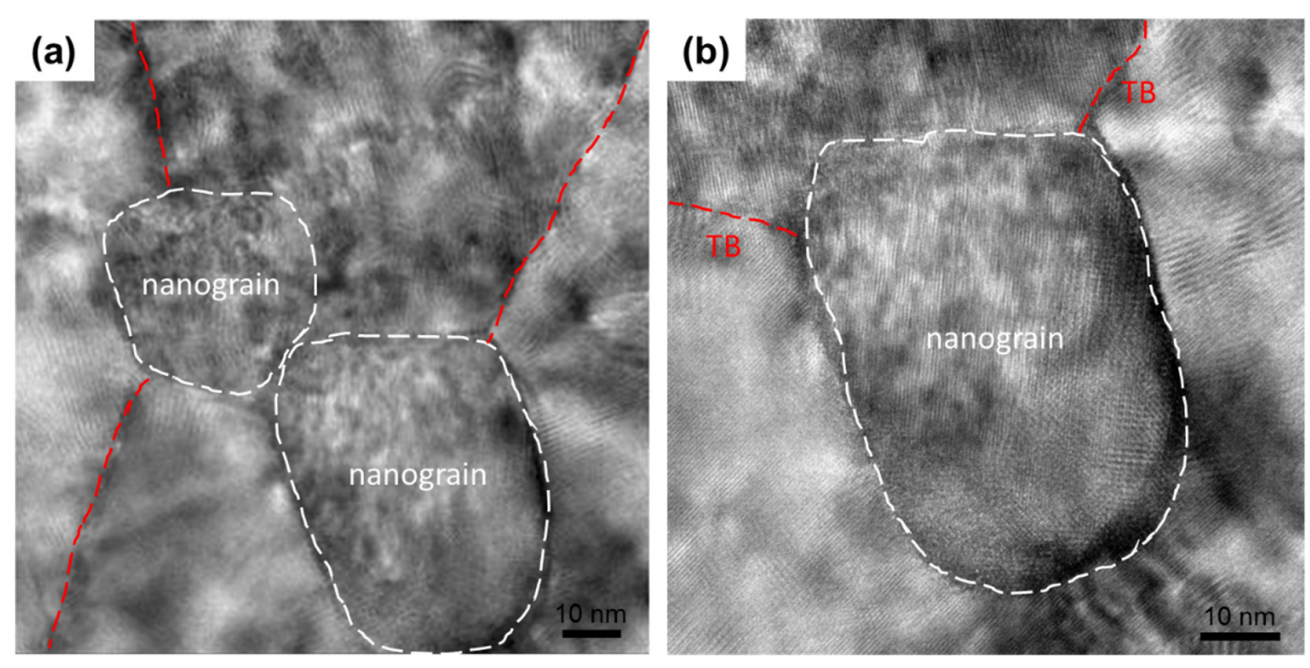

Fig. 7 TEM micrographs showing nanograins observed in the twin-blocks. Twin boundaries are indicated by red dashed lines, and profiles of the nanograins are highlighted with white dashed lines.

\subsubsection{Equiaxed nanograins}

Fig. 8 illustrates equiaxed nanograins area in a deformed sample. Inset shows the SAED pattern corresponding to this region, indicating the presence of equiaxed nanograins with a mean grain size of $\sim 93 \mathrm{~nm}$, see Fig. 4(c). These equiaxed grains are different from the nanograins in twin blocks in Fig. 7, which points to a different origin to be investigated. Note that these equiaxed nanograins only occupy a small volume fraction of the deformed structures (see Table.1). 


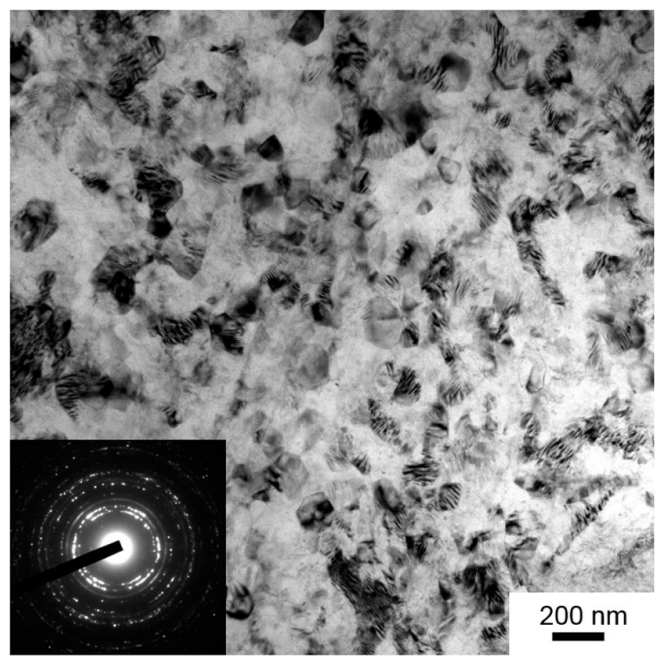

Fig. 8 TEM image showing the equiaxed nanograins area in a 2c sample.

\subsubsection{The volume fraction of structural features}

The volume fraction of the three structural features, cell blocks, twin blocks and equaixed nanograins are given in Table.1. In this table, the volume fraction of cell blocks and twin blocks are calculated based on a quantification of the distance between lamellar boundaries and twin boundaries, respectively. This table illustrates the significant difference between $1 \mathrm{c}$ and $2 \mathrm{c}$ samples and comparable parameters of $2 \mathrm{c}, 3 \mathrm{c}$ and $4 \mathrm{c}$ samples. Note the significant decrease in the density of twins after first and second cycle.

Table 1. Microstructural parameters

\begin{tabular}{|c|c|c|c|c|c|c|c|}
\hline \multirow{3}{*}{$\begin{array}{c}\text { ARB } \\
\text { samples }\end{array}$} & \multirow{3}{*}{$\begin{array}{c}\text { Equivalent } \\
\text { von Mises } \\
\text { strain }\end{array}$} & \multicolumn{6}{|c|}{ Microstructure } \\
\hline & & \multicolumn{2}{|c|}{ Cell blocks } & \multicolumn{2}{|c|}{ Twin blocks } & \multicolumn{2}{|c|}{$\begin{array}{l}\text { Equiaxed- } \\
\text { nanograins }\end{array}$} \\
\hline & & $\begin{array}{l}\text { Lamella } \\
\text { thickness } \\
(\mathrm{nm})\end{array}$ & $\begin{array}{l}\text { Vol. } \\
(\%)\end{array}$ & $\begin{array}{l}\text { Twin } \\
\text { thickness } \\
(\mathrm{nm})\end{array}$ & $\begin{array}{l}\text { Vol. } \\
(\%)\end{array}$ & $\begin{array}{c}\text { Grain } \\
\text { size }(\mathrm{nm})\end{array}$ & $\begin{array}{l}\text { Vol. } \\
(\%)\end{array}$ \\
\hline $1 \mathrm{c}$ & 0.8 & $\lambda=237$ & 59 & $\lambda=152$ & 41 & / & l \\
\hline $2 \mathrm{c}$ & 1.6 & $\lambda=191$ & 65 & $\lambda=138$ & 27 & $d=93$ & $\sim 8$ \\
\hline $3 c$ & 2.4 & $\lambda=182$ & 67 & $\lambda=132$ & 25 & $\mathrm{~d}=106$ & $\sim 8$ \\
\hline $4 c$ & 3.2 & $\lambda=182$ & 66 & $\lambda=126$ & 26 & $\mathrm{~d}=109$ & $\sim 8$ \\
\hline
\end{tabular}




\subsection{Mechanical properties}

Engineering stress-strain curves of the initial sample and ARB samples are shown in Fig. 9 where two stress-strain curves for each condition are include for the sake of clarity. The initial sample shows a high elongation of $21 \%$, but a low yield stress of 93 MPa. Compared with the initial sample, the elongations of the ARB samples show a large reduction; the yield stress has however increased to about 3 times as a result of the structural refinement. ARB samples show similar high yield stress. However, early fracture was clearly found in $1 \mathrm{c}$ sample with a total elongation about $1.2 \%$, which is lowest in all curves. 2c samples show best combination of strength and elongation, with a yield stress about $244 \mathrm{MPa}$ and total elongation about 5.3\%. With the increasing ARB cycles, 3-4c samples show a slow increase in yield stress and decrease in elongation. All mechanical property data and spacing of LBs or grain sizes are listed in Table 2.

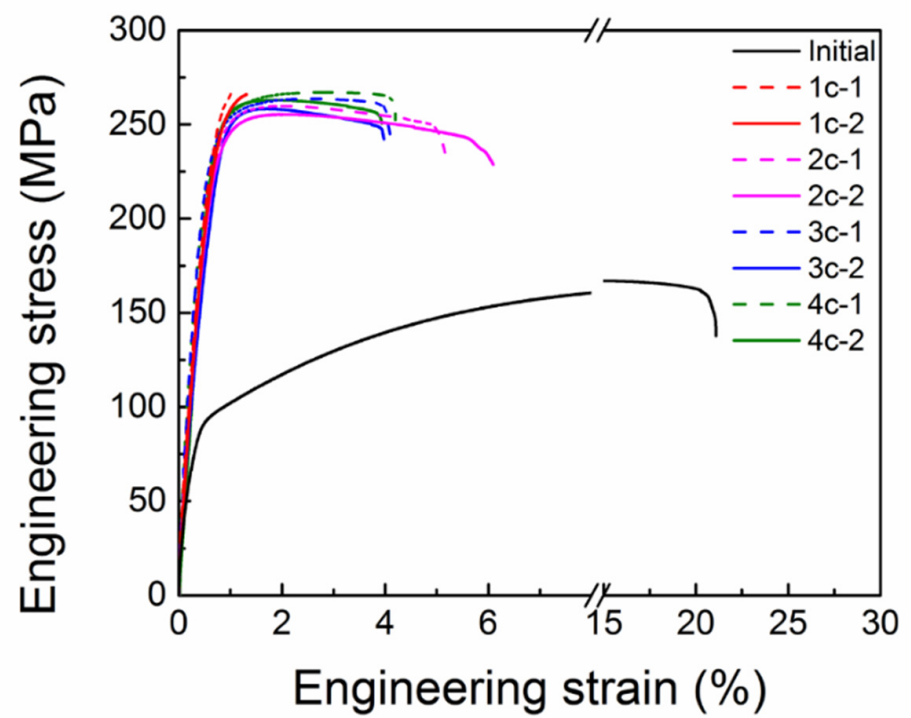

Fig. 9 Tensile stress-strain curves of the initial sample and the samples after ARB processing to $1 \mathrm{c}, 2 \mathrm{c}, 3 \mathrm{c}$ and $4 \mathrm{c}$. Tensile curves of two samples for each condition are included in the plot. 
Table 2. Mechanical properties

\begin{tabular}{ccccccc}
\hline & $\begin{array}{c}\sigma_{0.2} \\
(\mathrm{MPa})\end{array}$ & $\begin{array}{c}\sigma_{\mathrm{UTS}} \\
(\mathrm{MPa})\end{array}$ & $\begin{array}{c}\mathrm{e}_{\text {uniform }} \\
(\%)\end{array}$ & $\begin{array}{c}\mathrm{e}_{\text {total }} \\
(\%)\end{array}$ & $\begin{array}{c}\text { Vol. }(\%) \\
\text { of twins }\end{array}$ & $\begin{array}{c}\text { Grain size or } \\
\text { lamella thickness }\end{array}$ \\
\hline Initial & 93 & 168 & 16.6 & 21.1 & - & $\mathrm{d}=45 \mu \mathrm{m}$ \\
$1 \mathrm{c}$ & $259 \pm 5$ & $266 \pm 2$ & $1.2 \pm 0.1$ & $1.2 \pm 0.1$ & 41 & $\lambda=237 \mathrm{~nm}$ \\
$2 \mathrm{c}$ & $244 \pm 3$ & $257 \pm 2$ & $2.2 \pm 0.1$ & $5.3 \pm 0.4$ & 27 & $\lambda=191 \mathrm{~nm}$ \\
$3 \mathrm{c}$ & $248 \pm 4$ & $260 \pm 3$ & $2.3 \pm 0.5$ & $3.9 \pm 0.1$ & 25 & $\lambda=182 \mathrm{~nm}$ \\
$4 \mathrm{c}$ & $253 \pm 2$ & $265 \pm 2$ & $2.5 \pm 0.5$ & $4.0 \pm 0.1$ & 26 & $\lambda=182 \mathrm{~nm}$ \\
\hline
\end{tabular}

\section{Discussion}

\subsection{Microstructural evolution}

The microstructure of $\mathrm{Mg}-3 \mathrm{Gd}$ has been significantly refined by ARB processing to a total equivalent strain of 3.2. Three characteristic microstructural morphologies have been identified and characterized as: cell blocks, twin blocks and nanograins, all with boundary spacings of 100-200 nm, which illustrate a structural subdivision by low angle dislocation boundaries and high angle boundaries. The cell block structure reflects their evolution by dislocation based plasticity with activation of multiple glide systems. This structure has a clear resemblance to the cell block structure observed in bcc and fcc metals rolled to high strain. The twin block structure shows a morphology comparable to the cell block structure, a volume delineated by medium and high angle twin boundaries subdivided by low angle dislocation boundaries. Nanograins as a new structural feature are observed as part of the twin block structure and as equiaxed nanograins. Moreover, the structural evolution has its origin in dislocation and twinning based plasticity is quantified. The quantified microstructural results show a significant difference between 
$1 \mathrm{c}$ and $2 \mathrm{c}$ samples and comparable parameters of $2 \mathrm{c}, 3 \mathrm{c}$ and $4 \mathrm{c}$. In addition, the significant decrease in the density of twins after first and second cycle can be seen in Table.2. This differences may have its cause in a reduction in twin frequency when the grain size is reduced [30-33], which is the case as the average grain size of preheated specimens for 1cycle ARB rolling is about $40 \mu \mathrm{m}$ and about $10 \mu \mathrm{m}$ for 2 cycles ARB rolling.

\subsection{Structure-strength relationship}

A comparison of 1c data with $2 \mathrm{c}-4 \mathrm{c}$ data shows that the strength is the highest and the elongation is the lowest for the 1c sample, which may reflect an inhomogeneous microstructure and a high twin density in the 1c sample. This may suggest that twin boundaries show a stronger resistance to dislocation glide than lamellar boundaries. In addition, it is known that a high fraction of twins usually lead to premature fracture in magnesium alloys, which has its cause in the high stress concentration by twin-twin/twinboundary interaction [34]. With increasing ARB cycles, the volume fraction of twin blocks decreases from $41 \%$ to $26 \%$, while the volume fraction of cell block structure increases from $59 \%$ to $66 \%$, which is conducive to ductility improvement. In parallel, the structural refinement with increasing ARB cycles results in improvement in the strength and decrease in elongation for the $3 \mathrm{c}$ and $4 \mathrm{c}$ samples (Table 2). However, as both the volume fraction and the boundary spacing in the twin blocks differ from those in the cell blocks, a firm conclusion cannot be drawn based on the present data sets, which will be explored in future work.

A comparison of the present tensile results with the previous study [29] on the binary Mg-(2.75-4.65) Gd alloys (grain size: $10 \mu \mathrm{m})$ shows that the yield strength is increased from about $150 \mathrm{MPa}$ to $250 \mathrm{MPa}$, as a result of structural refinement obtained in the present study. However, the tensile elongation is significantly reduced from $20 \%$ 
to less than $5 \%$. Clearly this is not the optimal combination of strength and ductility achievable from the present alloy. Very recently, we investigated the grain size effects on the deformation mechanisms and tensile behaviour of the Mg-3Gd alloy and found that fine grained samples (grain size $<10 \mu \mathrm{m}$ ) show significantly improved combination of strength and ductility as compared with the samples of coarser grain sizes [35].

\section{Conclusions}

The microstructure of $\mathrm{Mg}-3 \mathrm{Gd}$ has been refined by ARB processing through four cycles to a total equivalent strain of 3.2. The deformed microstructure has been fully characterized by electron microscopy techniques and the conclusions are the following:

1. By plastic deformation the microstructure is refined to the nanometer level through formations of low angle dislocation boundaries and high angle boundaries. Three different morphologies have been identified and characterized as: cell blocks, twin blocks and nanograins, all having an average boundary spacing of 100-200 nm.

2. Nanograins as a new structural feature are observed as part of the twin block structure and as equiaxed nanograins.

3. A characterization of the cell block structure reflects their evolution by dislocation based plasticity with activation of multiple glide systems. The structure has a clear resemblance to the cell block structure observed in rolled bcc and fcc metals.

4. A characterization of the twin block structure shows a morphology comparable to the cell block structure, a volume delineated by medium and high angle twin boundaries subdivided by low angle dislocation boundaries. A similarity is also found in their contribution of boundary strengthening to the flow stress. 


\section{Acknowledgements}

The authors gratefully acknowledge supports from the State Key Research and Development Program of MOST, China (2016YFB0700400), the National Natural Science Foundation of China (No. 51421001) and Fundamental Research Fund of Central Universities of China (Grant No. 2018CDJDCL0019).

\section{Data availability}

The processed data required to reproduce these findings are available by email to the corresponding author: wugl@cqu.edu.cn.

\section{References}

[1] W.J. Joost, P.E. Krajewski, Towards magnesium alloys for high-volume automotive applications, Scr. Mater. 128 (2017) 107-112.

[2] I. Polmear, D. StJohn, J.F. Nie, M. Qian, Light alloys: metallurgy of the light metals, Butterworth-Heinemann, 2017.

[3] J.F. Nie, Precipitation and hardening in magnesium alloys, Metall. Mater. Trans. A 43 (2012) 3891-3939.

[4] M.E. Fine, Precipitation hardening of aluminum alloys, Metall. Mater. Trans. A 6 (1975) 625.

[5] M.A. Meyers, O. Vöhringer, V.A. Lubarda, The onset of twinning in metals: a constitutive description, Acta Mater. 49 (2001) 4025-4039.

[6] N. Hansen, Hall-Petch relation and boundary strengthening, Scr. Mater. 51 (2004) 801-806.

[7] H. Yu, Y. Xin, M. Wang, Q. Liu, Hall-Petch relationship in Mg alloys: A review, J. Mater. Sci. Technol. 34 (2018) 248-256. 
[8] R.Z. Valiev, R.K. Islamgaliev, I.V. Alexandrov, Bulk nanostructured materials from severe plastic deformation, Prog. Mater. Sci. 45 (2000) 103-189.

[9] R.Z. Valiev, Y. Estrin, Z. Horita, T.G. Langdon, M.J. Zechetbauer, Y.T. Zhu, Producing bulk ultrafine-grained materials by severe plastic deformation, JOM. 58 (2006) 33-39.

[10] Y. Saito, H. Utsunomiya, N. Tsuji, Novel ultra-high straining process for bulk materials development of the accumulative roll-bonding (ARB) process, Acta Mater. 47 (1999) 579-583.

[11] M.T. Pérez-Prado, D. Valle, O.A. Ruano, Grain refinement of Mg-Al-Zn alloys via accumulative roll bonding, Scr. Mater. 51 (2004) 1093-1097.

[12] W.J. Kim, S.I. Hong, Y.S. Kim, S.H. Min, H.T. Jeong, J.D. Lee, Texture development and its effect on mechanical properties of an AZ61 Mg alloy fabricated by equal channel angular pressing, Acta Mater. 51 (2003) 3293-3307.

[13] K. Edalati, A. Yamamoto, Z. Horita, T. Ishihara, High-pressure torsion of pure magnesium: evolution of mechanical properties, microstructures and hydrogen storage capacity with equivalent strain, Scr. Mater. 64 (2011) 880-883.

[14] M. Richert, Q. Liu, N. Hansen, Microstructural evolution over a large strain range in aluminium deformed by cyclic-extrusion-compression, Mater. Sci. Eng. A 260 (1999) 275-283.

[15] Q. Chen, D.Y. Shu, J. Lin, Y. Wu, X.S. Xia, S.H. Huang, Z.D. Zhao, O.V. Mishin, G.L. Wu, Evolution of Microstructure and Texture in Copper during Repetitive Extrusion-Upsetting and Subsequent Annealing, J. Mater. Sci. Technol. 33 (2017) 690-697.

[16] M. Chen, E. Ma, K.J. Hemker, H. Sheng, Y. Wang, X. Cheng, Deformation twinning in nanocrystalline aluminum, Science. 300 (2003) 1275-1277. 
[17] A.P. Zhilyaev, G.V. Nurislamova, B.K. Kim, M.D. Baró, J.A. Szpunar, T.G. Langdon, Experimental parameters influencing grain refinement and microstructural evolution during high-pressure torsion, Acta Mater. 51(3) (2003) 753-765.

[18] F.K. Yan, G.Z. Liu, N.R. Tao, K. Lu, Strength and ductility of 316L austenitic stainless steel strengthened by nano-scale twin bundles. Acta Mater. 60 (2012) 10591071.

[19] H. Yoshinaga, R. Horiuchi, Deformation mechanisms in magnesium single crystals compressed in the direction parallel to hexagonal axis, Trans. Jpn. Inst. Met. 4 (1963) $1-8$.

[20] J.W. Christian, S. Mahajan, Deformation twinning, Prog. Mater. Sci. 39 (1995) 1157.

[21] S. Sandlobes, S. Zaefferer, I. Schestakow, S. Yi, R. Gonzalez-Martinez, On the role of non-basal deformation mechanisms for the ductility of $\mathrm{Mg}$ and $\mathrm{Mg}-\mathrm{Y}$ alloys, Acta Mater. 59 (2011) 429-439.

[22] S. Sandlobes, M. Friák, J. Neugebauer, D. Raabe, Basal and non-basal dislocation slip in Mg-Y, Mater. Sci. Eng. A 576 (2013) 61-68.

[23] M.H. Yoo, J.R. Morris, K.M. Ho, S.R. Agnew, Nonbasal deformation modes of HCP metals and alloys: role of dislocation source and mobility, Metall. Mater. Trans. A $33(2002) 813-822$.

[24] S.R. Agnew, J.A. Horton, M.H. Yoo, Transmission electron microscopy investigation of $<\mathrm{c}+\mathrm{a}>$ dislocations in $\mathrm{Mg}$ and $\alpha$-solid solution $\mathrm{Mg}$-Li alloys, Metall. Mater. Trans. A 33 (2002) 851-858.

[25] X.Y. Shi, Y. Liu, D.J. Li, B. Chen, X.Q. Zeng, J. Lu, W.J. Ding, Microstructure evolution and mechanical properties of an Mg-Gd alloy subjected to surface mechanical attrition treatment, Mater. Sci. Eng. A 630 (2015) 146-154. 
[26] N. Hansen, New discoveries in deformed metals, Metall. Mater. Trans. A 32 (2001) 2917-2935.

[27] D.A. Hughes, N. Hansen, Plastic deformation structures. Vol 9: Metallography and Microstructures, ASM handbook, 2004.

[28] X. Huang, G. Winther, Dislocation structures. Part I. Grain orientation dependence, Philos. Mag. 87 (2007) 5189-5214.

[29] N. Stanford, D. Atwell, M.R. Barnett, The effect of Gd on the recrystallisation, texture and deformation behaviour of magnesium-based alloys, Acta Mater. 58(20) (2010) 6773-6783.

[30] M.R. Barnett, Z. Keshavarz, A.G. Beer, D. Atwell, Influence of grain size on the compressive deformation of wrought Mg-3A-1Zn, Acta Mater. 52(2004) 50935103.

[31] M.R. Barnett, A rationale for the strong dependence of mechanical twinning on grain size, Scr. Mater. 59 (2008) 696-698.

[32] H. Fan, S. Aubry, A. Arsenlis, J.A. El-Awady, Grain size effects on dislocation and twinning mediated plasticity in magnesium, Scr. Mater. 112 (2016) 50-53.

[33] Q. Yu, R.K. Mishra, A.M. Minor, The effect of size on the deformation twinning behavior in hexagonal close-packed Ti and Mg, JOM. 64 (2012) 1235-1240.

[34] M. Lentz, M. Risse, N. Schaefer, W. Reimers, I.J. Beyerlein, Strength and ductility with $\{1011\}-\{1012\}$ double twinning in a magnesium alloy, Nat. Comm. 7 (2016) 11068.

[35] X. Luo, Z.Q. Feng, T.B. Yu, J.Q. Luo, T.L. Huang, G.L. Wu, N. Hansen, X. Huang, Transitions in mechanical behavior and in deformation mechanisms enhance the strength and ductility of $\mathrm{Mg}-3 \mathrm{Gd}$, Acta Mater. In Press, doi.org/10.1016/j.actamat.2019.11.034 